\title{
PERANCANGAN ALAT BANTU MESIN BUBUT UNTUK MENAIKKAN GAYA CEKAM \\ (Studi Kasus untuk produk poolschif, part dari Mikroskop Elektron)
}

\author{
NEFLI YUSUF, AGUS KAMIL \\ Fakutlas Teknik UMSB ${ }^{1}$ \\ nelfiyusuf@umsb.ac.id ${ }^{1}$
}

\begin{abstract}
Abstrak -Produk poolschijf merupakan bagian (part) dari mikroskop elektron berbentuk pipih karena itu sulit dicekamketikadimesin oleh mesin bubut CNC (Computer Numerical Control).Pada penelitian ini dilakukan perancangan alat bantu (fixture) untuk menaikkan gaya cekam ini agar dapat dipenuhi parameter permesinan optimum yang diinginkan. Parameter permesinan optimum yang ingin dicapai adalah kecepatan potong (cutting speed) $200 \mathrm{~m} / \mathrm{min}$, kecepatan makan (feed) 0,3 mm/put, kedalaman potong $1,5 \mathrm{~mm}$ pada kecepatan spindle 1500 rpmmenggunakan pahat insert Taegutec, grade TT5100(P20). Sebelumnya tanpa menggunakan alat bantu kondisi permesinan adalah kecepatan potong (cutting speed) $160 \mathrm{~m} / \mathrm{min}$, kecepatan makan (feed) $0,15 \mathrm{~mm} /$ put, kedalaman potong 1,0 $\mathrm{mm}$. Dari hasil perancangan alat ini diperoleh kenaikkan gaya cekam 40,91\% menjadi 2,2 Mpa sekaligus menurunkan gaya centrifugal serta menambah kekakuan benda kerja sehingga kondisi pemotongan optimum yang diinginkan dapat tercapai. Dipihak lain terjadi pengurangan waktu permesinan dan pengurangan bahan baku produk. Demikian penggunaan alat bantu ini dapat menurunkan ongkos produksi serta menghemat bahan baku.
\end{abstract}

Kata Kunci: alat bantu (fixture), mesin bubut $\mathrm{CNC}$, parameter permesinan, ongkos produksi

Abstract - The poolschijf product is a part of electron microscope formed a flat-shaped so that it is difficult to be gripedin a CNC (Computer Numerical Control) lathe machine. In this research, it design the fixture tools to increase the griping force in order to meet the optimum parameters of machine design. The optimum machining parameters to be achieved are $200 \mathrm{~m} /$ minof cutting speed, $0.3 \mathrm{~mm} /$ put of feed rate, $1.5 \mathrm{~mm}$ of slice cut at $1500 \mathrm{rpm}$ of spindle speed using insert chisel. Taegutec grade TT5100 (P20). Previously without the use of machine tool conditions are cutting speed $160 \mathrm{~m} / \mathrm{min}$, feeding speed (feed) $0.15 \mathrm{~mm} /$ put, $1.0 \mathrm{~mm}$ cutting depth. From the results of this tool design is obtained the increasing of burden of $40.91 \%$ that is $2.2 \mathrm{Mpa}$ as well as reduce the centrifugal force and increase the rigidity of workpiece so that the desired optimum cutting conditions can be achieved. On the other hand there is a reduction in machining time and reduction of raw materials of the product. Thus the use of this tool can reduce the cost of production and save raw materials.

Keywords: fixture, CNC lathe, machining parameters, production cost

\section{PENDAHULUAN}

Proses manufaktur menggunakan mesin perkakas sampai saat ini masih tetap merupakan proses yang dominan digunakan $(60 \%-80 \%)$ untuk pembuatan bagian (part) suatu mesin dibanding jenis proses yang lain, seperti proses pengelasan (welding), proses pembentukan (forming) dan proses pengecoran (casting) karena mesin perkakas lebih unggul dalam menghasilkan ketepatan dan ketelitian permukaan sehingga dapat memenuhi toleransi suaian pasanggannya, demikian Taufiq Rochim (2007)[5]. Mesin perkakas yang paling banyak digunakan pada proses manufaktur adalah mesin bubut (lathe) dimana gerak utamanya adalah benda kerja berputar sementara pahat (tool) yang umumnya single cutting point bergerak searah sumbu rotasi atau translasi.

Penentuan parameter permesinan, seperti gaya potong, gerak makan, putaran spindle, kekakuan, sifat material dan lainnya, mempengaruhi kondisi permesinan. Untuk mendapatkan kondisi permesinan yang optimum sering membutuhkan perangkat alat bantu (fixture). Agar diperoleh gaya potong/gerak makan yang tinggi diperlukan kekakuan benda kerja (workpiece) yang tinggi 
pula, kecuali untuk mendapatkan hasil pengerjaan yang baik. Kompromi penentuan antara penentuan kecepatan pengerjaan dengan hasil pengerjaan permukaan yang diinginkan akan mempengaruhi biaya dan waktu, baik itu dikerjakan oleh mesin konvensional maupun mesin CNC(Computer Numerical Control).

Proses permesinan menggunakan mesin bubut CNCdiperuntukkan untuk menghasilkan produk masal dengan jumlah dan ketelitian yang tinggi. Berbeda dengan mesin konvensional yang sangat dipengaruhi oleh keterampilan operator, mesin $\mathrm{CNC}$ sangat dipengaruhi oleh pengetahuan teoritis dan kreatifitasoperatornya.Walaupun sulit untuk menilai seorang operator berdasarkan keberhasilan pembelajarannya secara teori (cognitive),kepandaian (skill) dan keterampilan (psychomotor) tetapi penulis ingin menekankan bahwa aspek teori dan kreatifitas merupakan hal yang sangat menentukan untuk membuat mesin CNC dapat berjalan produktif.Di negara maju masyarakatnya sangat memberikan penghargaan terhadap aspek teori dan kreatifitas ini, tetapi masyarakat kita kadang melecehkannya dengan sanggahan "itu kan teori?"

Makalah ini mengungkapide rekayasa pembuatan produk poolschijfmenggunakanalat bantuyang dikerjakan oleh mesin perkakas bubut CNC dalam menaikkan efisiensi, efektifitas dan produktifitas kerja mesin. Selanjutnya dianalisis melalui perumusan teoritis berbagai sumber yang relevan untuk kemudian dibuktikan dalam aplikasinya.Betapapun sederhananya ide yang dikemukakan tetapi apabila dianalisis melalui ilmu pengetahuan dan teknologi yang komprehensiftentu akan memberikan keuntungan dan pemahaman yang baik sebagai referensi terhadap berbagai kasus serupa lainnya.

Secara sederhana mesin bubut dapat beroperasi maksimum melalui parameter kecepatan potong, kecepatan makan, kedalaman potong yang tinggi. Tetapi parameter ini selalu dibatasi oleh kemampuan dan kondisi mesin serta pahat yang digunakan, alih-alih juga dipengaruhi oleh ketelitian proses yang diinginkan, lingkungan kerja dan lainnya. Kondisi pencekaman benda kerja (workpiece) menggunakan alat bantu sederhana, yang akan dibahas berikut ini,dapat memenuhi kondisi operasi optimumproses yang diinginkan.

\section{DASAR TEORI}

\section{Terminologi Proses Bubut}

Ada tiga parameter utama dalam proses bubut yaitu kecepatan potong $(V)$, pemakanan $(f)$, dan kedalaman potong $(a)$. Pemilihan atau penerapan harga dari tiga parameter pemesinan tersebut ditentukan oleh bahan produk yang dikerjakan, jenis insert yang dipakai dan kondisi pemotongan, dalam kasus ini kondisi pencekaman produk.Menurut Rochim (2007) pada setiap proses pemesinan ada lima elemen dasar yang perlu dipahami dan berhubungan satu sama lainnya, yaitu:

a. Kecepatan potong $(V)$,

b. Kecepatan makan $\left(V_{f}\right)$,

c. Kedalaman potong $(a)$,

d. Waktu pemotongan $\left(t_{c}\right)$ dan

e. Sudut potong utama $\left(\kappa_{\mathrm{r}}\right)$

Hubungan kelima elemen dasar tersebut sesuai persamaan yang diturunkan berdasarkan Gambar 1.berikut:

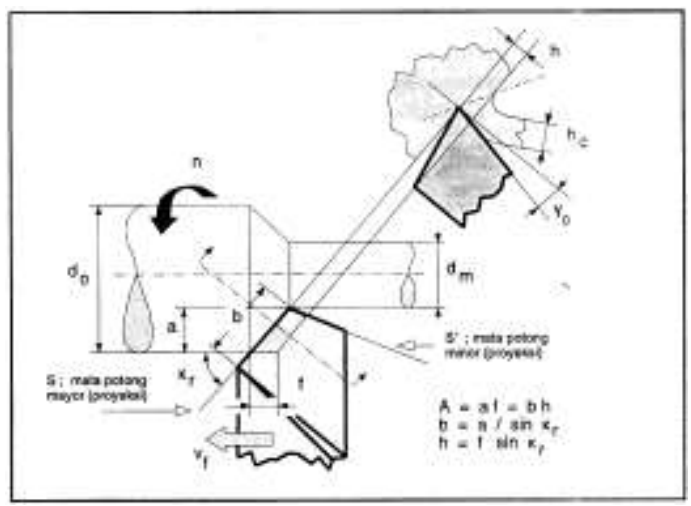

Gambar 1. Proses bubut, Taufiq Rochim (2007)

Geometri benda kerja:

$d_{o}=$ diameter awal [mm]

$d_{m}=$ diameter akhir $[\mathrm{mm}]$

$l_{t}=$ panjang pemesinan $[\mathrm{mm}]$

Geometri pahat:

$\kappa_{\mathrm{r}}=$ sudut potong utama $\left[{ }^{\circ}\right]$

$\Upsilon_{\mathrm{o}}=$ sudut geram $\left[{ }^{\circ}\right]$

Kondisi pemesinan:

$$
\begin{aligned}
a & =\text { kedalaman pemakanan }=\frac{\mathbb{d}_{0}-d_{m}}{2}[\mathrm{~mm}] \\
f & =\text { pemakanan [mm/putaran] } \\
n & =\text { putaran poros utama [rpm] }
\end{aligned}
$$

Dengan diketahuinya besaran-besaran di atas sehingga kondisi pemotongan dapat diperoleh sebagai berikut: 
- Gaya potong Fvdapat dinyatakan sebagai rumus empirik berikut:

$$
\mathrm{F}_{\mathrm{V}}=\mathrm{k}_{\mathrm{s}} \cdot \mathrm{A}
$$

Dengan:

$\mathrm{F}_{\mathrm{V}}$ = gaya potong; $\mathrm{N}$

$\mathrm{A}=$ penampang geram sebelum terpotong $\left[\mathrm{mm}^{2}\right]$

$=\mathrm{b} . \mathrm{h}=\mathrm{a} . \mathrm{f}$ (lihat Gambar 1.)

$\mathrm{k}_{\mathrm{s}}=$ gaya potong spesifik (specific cutting force $)\left[\mathrm{N} / \mathrm{mm}^{2}\right]$, disebut juga energi potong spesifik $\left[\mathrm{J} / \mathrm{cm}^{3}\right]$

$=k_{g 1,1} \cdot h^{-z}$

$\mathrm{k}_{\mathrm{s} 1.1}=$ gaya potong spesifik referensi $\left[\mathrm{N} / \mathrm{mm}^{2}\right]$

$\mathrm{h}=$ tebal geram sebelum terpotong $\left[\mathrm{mm}^{2}\right]$

$\mathrm{z}=$ pangkat tebal geram (rata-rata berharga $=0.2$ )

- Waktu pemotongan:

$$
t_{c}=\frac{l_{t}}{f \cdot n}
$$

Dengan:

$t_{c}=$ waktu pemotongan (dalam

satu kali lintasan) [menit]

$$
l_{t}=\text { panjang pemesinan }[\mathrm{mm}]
$$

Gaya yang timbul sewaktu proses pemotongan berlangsung harus dapat diserap dan ditransmisikan oleh pemegang benda kerja (chuck), pada Gambar 2.dapatdilihat gaya dan arahnya yang muncul sewaktu proses pemotongan berlangsung.

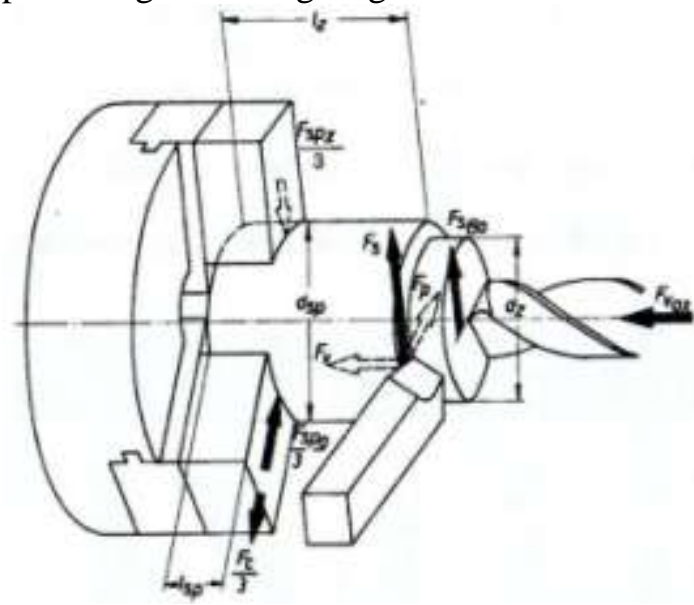

Gambar 2. Gaya dan titik pencekaman pada proses bubut

(http://www.roehm.biz/fileadmin/products/me dia/en/DC0000221.PDF)
Keterangan:

$\mathrm{F}_{\mathrm{S}}$ = gaya potong utama

$\mathrm{F}_{\mathrm{SBo}}=$ gaya potong pada axial (drill)

$\mathrm{F}_{\mathrm{vax}}=$ gaya pengumpanan (feed force)

$\mathrm{F}_{\mathrm{spz}}=$ gripping force yang dibutuhkan

(tanpa perhitungan efek dari angular speed)

$\mathrm{F}_{\mathrm{C}}=$ gaya sentrifugal dari rahang

$\mathrm{F}_{\mathrm{spo}}=$ total gripping forcepada kondisi

chuck diam

$\mathrm{l}_{\mathrm{z}}=$ panjang dari yang diproses ke titik

pusat pencekaman

$\mathrm{d}_{\mathrm{z}}=$ diameter yang dibubut

$\mathrm{d}_{\mathrm{sp}}=$ diameter yang diklem

$1_{\mathrm{sp}}=$ panjang yang diklem

- Untuk mengetahui besarnya gaya pencekaman yang dibutuhkan, digunakan rumus berikut:

$$
F_{s p z}=\frac{F_{S} \cdot S_{Z}}{\mu_{s p}} \cdot \frac{d_{z}}{d_{s p}}
$$

Dengan:

$\mathrm{F}_{\mathrm{spz}}=$ gaya cekam pada kondisi chuck diam [N]

$\mathrm{F}_{\mathrm{S}}=$ gaya potong utama (main cutting force); atau $\mathrm{F}_{\mathrm{v}}=\mathrm{k}_{\mathrm{s}}$. a . f ; $\mathrm{N}$

$\mathrm{d}_{\mathrm{z}}=$ diameter yang dibubut; $\mathrm{mm}$

$\mathrm{d}_{\mathrm{sp}}=$ diameter yang diklem; $\mathrm{mm}$

$\mu_{\mathrm{sp}}=$ koefisien friksi (friksi/gesekan antara rahang chuck dan benda kerja)

$\mathrm{S}_{\mathrm{Z}}=$ faktor keselamatan (safety factor), nilainya harus $\geq 2$

berikut:

Untuk harga $\mu_{\mathrm{sp}}$ mengacu kepada tabel

Tabel 1.Harga koefisien friksi $\left(\mu_{\mathrm{sp}}\right)$

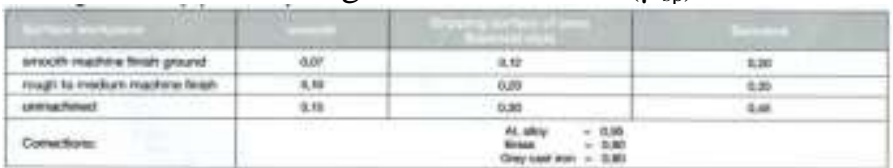

Gaya pencekaman yang dibutuhkan dengan mempertimbangkan gaya sentrifugal yang terjadi:

$$
F_{s p o}=S_{s p} \cdot\left(F_{s p} \pm F_{C}\right)
$$

Dengan:

$F_{s p o}=$ gaya pencekaman yang dibutuhkan pada kondisi chuck berputar; $\mathrm{N}$ 
$F_{C}=$ jumlah gaya sentrifugal dari rahang chuck; $\mathrm{N}$

$S_{s p}=$ faktor keselamatan untuk chuck mengacu kepada rekomendasi VDI 3106 , dan nilainya $\geq 1,5$

$\pm=$ tanda $[+]$ digunakan untuk pencekaman luartanda [-] digunakan untuk pencekaman dalam.

- Sedangkan gaya sentrifugal dari chuck dihitung dengan menggunakan rumus berikut:

$$
F_{c}=\Sigma\left(m \cdot r_{g}\right)\left(\frac{\pi \cdot n}{30}\right)^{2}
$$

di mana,

$F_{C}=$ gaya sentrifugal $[\mathrm{N}]$

$m=$ berat rahang per set (base dan top jaws) $[\mathrm{kg}]$

$r_{s}=$ jarak dari titik tengah rahang chuck ke sumbu (radius)[m]

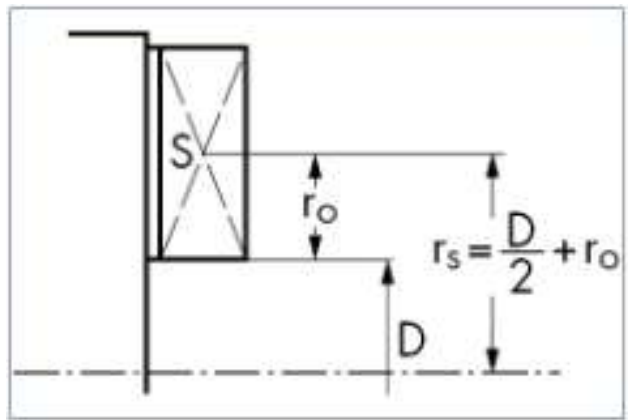

Gambar 3. Untuk mencari harga $r_{s}$ dalam menghitung gaya sentrifugal

(http://www.schunk.com/schunk_files/attachm ents/lathe chuck chuck jaws technology DE _EN.pdf)

\section{Pengertian Alat Bantu (Fixture)}

Alat bantuyang dimaksud adalah alat untuk menempatkan dan memegang benda kerja sewaktu proses pemesinan berlangsung. Pada penggunaannya fixture harus dikunci dengan kuat pada mesin yang menggunakannya. Fixture biasanya diklasifikasikan berdasarkan kepada jenis mesin dimana fixture tersebut akan digunakan, milling fixture adalah fixture yang digunakan di mesin milling dan lathe fixture adalah fixture yang digunakan di mesin lathe (Henriksen, 1973).

\section{Prinsip-Prinsip Perancangan Fixture}

Henriksen (1973) menguraikan hal-hal yang harus diperhatikankan oleh seorang perancang fixtureketika melakukan proses perancangan:

- Ukuran dan bentuk dari produk.

- Tipe dan jenis material dari produk.

- Jenis proses pemesinan yang akan dilakukan.

- Tingkat ketelitian (accuracy) dari produk yang harus diproduksi.

- Jumlah produk yang akan diproduksi.

- Permukaan dari locating dan clamping.

Bagian-bagian utama fixture beserta fungsinya adalah sebagai berikut:

a)Locating/Locator, untuk menahan dan memposisikan benda kerja secara tepat pada posisi yang diinginkan.

b) Clamping, untuk memegang/mencekam benda kerja secara aman pada posisinya selama proses pemotongan berlangsung.

c) Supporting, bagian untuk menahan benda kerja ketika mendapat tekanan dari tool sewaktu proses pemotongan berlangsung.

d) Fixture body, adalah bagian utama dari fixture tempat dimana beradanya locating, clamping dan supporting.

\section{Analisa Data dan Perhitungan}

Data yang dianalisa dan dihitung pada bagian ini adalah:

- Parameter Pemesinan (cutting parameters)

- Waktu Pemotongan (cutting time)

- Gaya Potong (cutting force)

- Gaya Sentrifugal (centrifugal corce)

- Gaya Pencekaman (clamping force)

Untuk data-data tersebut diatas diambil dari data-data yang dimiliki oleh operasi 20 dan operasi 30pada proses pengerjaan bubut roughing external.

1. Data Teknis dari bahan Produk Nama/Jenis Bahan : Ferro Nickel 48 1.3926 DIN 17405-RNi12

Kandungan Karbon $\quad: 0.02 \%$

Tegangan Tarik $\quad: 750 \mathrm{~N} / \mathrm{mm}^{2}$

Kekerasan : $97 \mathrm{HRB}$ 
2. Data Tool/Insertyang dianalisa

Tabel 2. Jenis dan tipe insert yang diteliti

\begin{tabular}{|c|c|c|c|c|}
\hline $\begin{array}{c}\text { No } \\
\text { Tool }\end{array}$ & Proses & Tool/Insert & $\begin{array}{c}\text { Gr } \\
\text { ade }\end{array}$ & $\begin{array}{c}\text { M } \\
\text { er }\end{array}$ \\
\hline \multirow{4}{*}{0101} & & CNMG & TT & T \\
& -Roughing & $120408-$ & 510 & $\mathrm{~A}$ \\
& External & ML & 0 & E \\
& & (Shank: & $(\mathrm{P} 2$ & $\mathrm{G}$ \\
\hline
\end{tabular}

3. Parameter Pemesinan yang Dipakai (parameter operasi 30)

Tabel 3. Parameter pemesinan operasi 30

\begin{tabular}{|c|c|c|c|c|}
\hline $\begin{array}{l}\text { Nomor } \\
\text { Operasi }\end{array}$ & $\begin{array}{c}\text { Cutting } \\
\text { Speed } \\
(\mathbf{m} / \mathbf{m i n}) \\
-\mathbf{V c}\end{array}$ & $\begin{array}{c}\text { Feed } \\
(\mathbf{m m} / \mathbf{r}) \\
-\mathbf{f}\end{array}$ & $\begin{array}{c}\text { Depth } \\
\text { of cut } \\
(\mathbf{m m}) \\
-\mathbf{a}\end{array}$ & $\begin{array}{c}\text { Spin } \\
\text { dle } \\
\text { Spee } \\
\mathbf{d}\end{array}$ \\
\hline 30 & 160 & 0,15 & 1,0 & 1500 \\
\hline
\end{tabular}

4. Parameter Pemesinan yang Dijadikan Target (parameter operasi 20)

Tabel 4. Parameter pemesinan operasi 20

\begin{tabular}{|c|c|c|c|c|}
\hline $\begin{array}{c}\text { Nomor } \\
\text { Operasi }\end{array}$ & $\begin{array}{c}\text { Cutting } \\
\text { Speed } \\
(\mathbf{m} / \mathbf{m i n}) \\
-\mathbf{V c}\end{array}$ & $\begin{array}{c}\text { Feed } \\
(\mathbf{m m} / \mathbf{r}) \\
-\mathbf{f}\end{array}$ & $\begin{array}{c}\text { Depth } \\
\text { of cut } \\
(\mathbf{m m}) \\
-\mathbf{a}\end{array}$ & $\begin{array}{c}\text { Spindle } \\
\begin{array}{c}\text { Speed } \\
(\mathbf{r p m})\end{array}\end{array}$ \\
\hline 20 & 200 & 0,3 & 1,5 & 1500 \\
\hline
\end{tabular}

5. Kondisi Proses pemesinan Operasi 20 dan Operasi 30

Tabel 5. Kondisi proses pemesinan operasi 20 dan operasi 30

\begin{tabular}{|c|c|c|c|c|}
\hline No & Keterangan & Op.20 & Op.30 & $\begin{array}{l}\text { Satu } \\
\text { an }\end{array}$ \\
\hline & A. Waktu & & & \\
\hline \multirow[t]{2}{*}{1} & $\begin{array}{c}\text { Waktu Pemotongan (1x } \\
\text { lintasan) }\end{array}$ & 0.19 & 0.32 & $\begin{array}{l}\text { meni } \\
\mathrm{t}\end{array}$ \\
\hline & B. Pencekaman & & & \\
\hline 2 & $\operatorname{rahang}($ Jaws $)$ & rd Jaws & Jaws & \\
\hline 3 & Chuck Pressure & 2.20 & 1.30 & $\mathrm{MPa}$ \\
\hline 4 & Panjang yg dicekam & 10.00 & 4.50 & $\mathrm{~mm}$ \\
\hline \multirow[t]{2}{*}{5} & Panjang yang dikerjakan & 7.00 & 11.50 & $\mathrm{~mm}$ \\
\hline & C. Gaya $\begin{array}{c}\text { Yang Terjadi } \\
\text { (perhitungan) }\end{array}$ & & & \\
\hline 6 & Cutting Force & $1,423.00$ & 545.00 & $\mathrm{~N}$ \\
\hline 7 & Centrifugal Force & $2,741.00$ & $\begin{array}{r}4,871 . \\
00\end{array}$ & $\mathrm{~N}$ \\
\hline 8 & $\begin{array}{c}\text { Clamping Force } \\
\text { dibutuhkan }\end{array}$ & $26,790.00$ & $\begin{array}{r}29,291 \\
.00\end{array}$ & $\mathrm{~N}$ \\
\hline
\end{tabular}

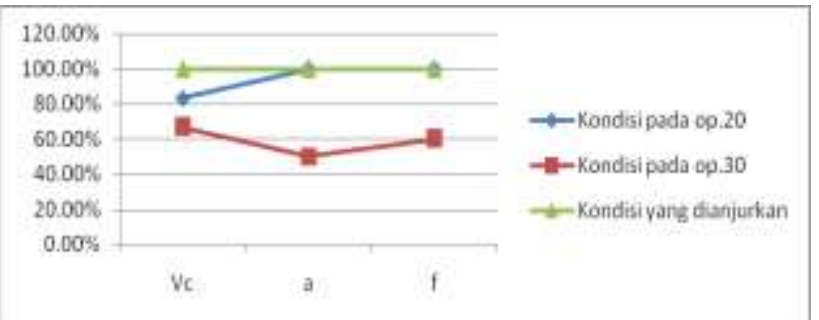

Gambar 5.Grafik kondisi parameter pemesinan yang dipakai pada operasi 20 dan operasi 30 dibandingkan dengan parameter pemesinan yang direkomendasikan oleh Tool Manufacturer.

Dari Gambar 5.diatas terlihat bahwa kondisi penggunaan parameter pemesinan $(V c, a$ dan $f$ ) pada operasi 30 kondisinya tidak optimal dibandingkan dengan operasi 20 dan rekomendasi tool manufacturer (taegutec).

"Gambar (6)" di bawah memperlihatkan kondisi pencekaman pada operasi 30 mengacu kepada operasi 20, adalah:

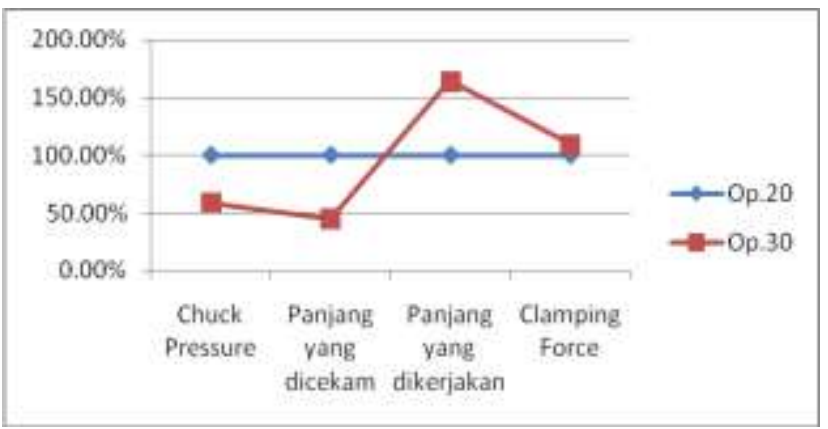

Gambar 6. Grafik kondisi pencekaman operasi 30 mengacu kepada kondisi pencekaman operasi 20.

Dari Gambar 6.diatas terlihat bahwasanya kondisi pencekaman operasi 30 adalah sebagai berikut:

- Chuck pressure 40\% lebih rendah dibanding operasi 20

- Panjang produk yang dicekam 55\% lebih pendek dari operasi 20

- Panjang produk yang dikerjakan 64\% lebih panjang dari operasi 20

- Clamping force yang dibutuhkan 9\% harus lebih besar dari operasi 20

Sehingga dari kondisi pencekaman yang sekarang dipakai oleh operasi 30 tidak memungkinkan untuk menerapkan parameter 
pemesinan ( $V c, a$ dan $f$ ) yang optimal seperti pada operasi 20, dikarenakan oleh kondisi sebagai berikut:

- Kekerasan produk 42\% lebih lunak daripada kekerasan pencekam (soft jaws)nilai kekerasan ini akan berpengaruh kepada penggunaan chuck pressure untuk gaya pencekaman.

- Panjang yang dicekam hanya $28 \%$ dari total panjang produk - perbandingan panjang ini akan berpengaruh kepada penggunaan depth of cut (a).

\section{Perancangan Lathe Fixture}

\section{Supporting, Locatingdan Clamping}

Mengacu kepada kondisi produk hasil operasi 20, maka kondisi rancangan untuk supporting, locating dan clampinguntuk lathe fixtureadalah seperti gambar di bawah:

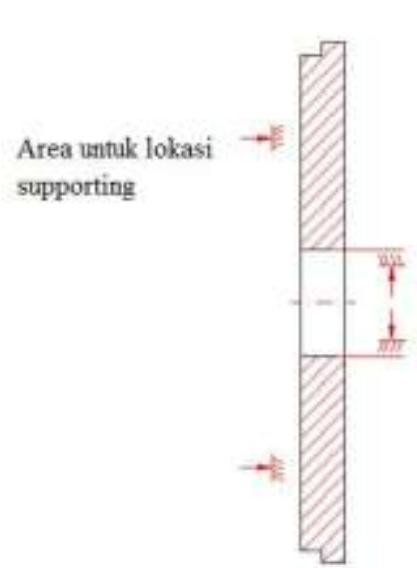

(a)

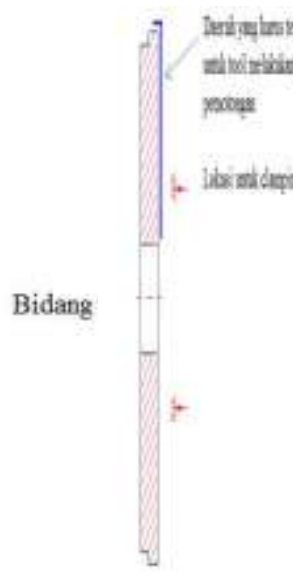

(b)
Gambar 7. Rancangan dari (a) supporting, locating dan (b) clamping

Agar menghasilkan produk dengan variasi ukuran yang terkontrol dan juga memudahkan dalam loading dan unloading produk dari lathe fixture, maka harga toleransi yang dipakai untuk produk dan locating adalah $24 \mathrm{H} 7 / 24 \mathrm{~g} 6$.

\section{Body}

Dengan pertimbangan fungsi body sebagai tempat dudukan dari supporting dan locating dan yang akan menahan cutting forcedari tool yang ditransmisikan melalui permukaan produk dan juga yang akan secara langsung bersentuhan dan dicekam olehchuck (jaws), maka bahan dari body menggunakan steel C45 yang memiliki kekerasan HRB 207255 dengan bentuk rancangan seperti "Gambar (8)" di bawah:

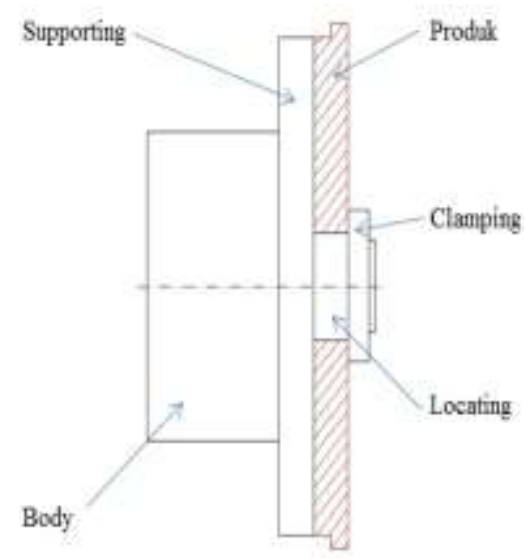

(a)

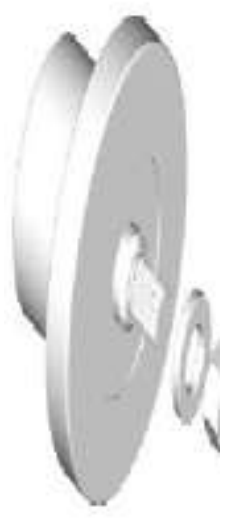

(b)
Gambar 8. Rancangan untuk body, supporting, locating dan clamping dari lathe fixture, (a) tampilan 2D, dan (b) tampilan 3D

Dari hasil rancangan-rancangan tadi, maka gambar lathe fixture adalah seperti berikut:

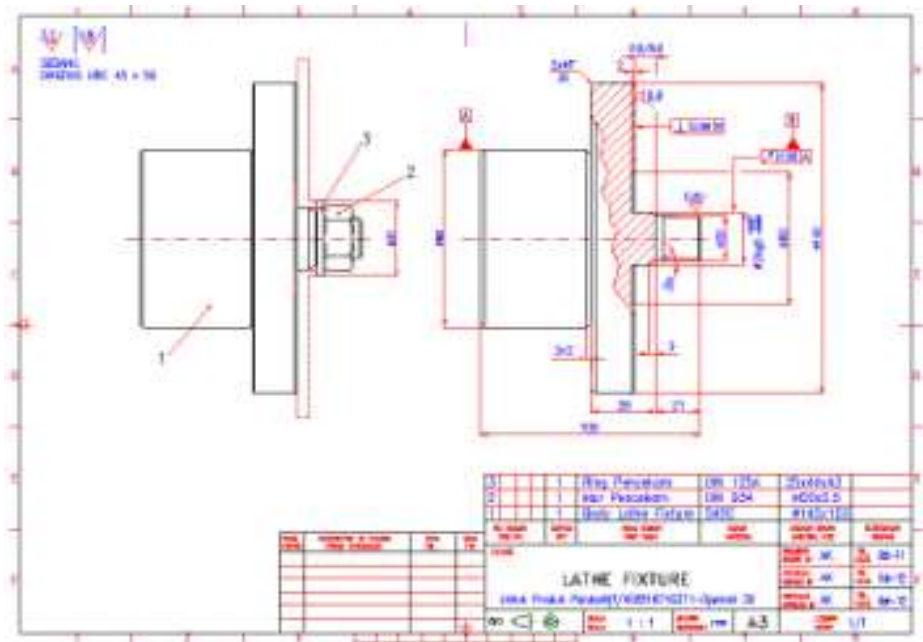

Gambar 9.Lathe fixture hasil rancangan

\section{Evaluasi dan Analisa Hasil Rancangan}

Untuk mendapatkan kesesuaian antara target yang ingin dicapai dengan hasil rancangan, maka gambar di bawah memperlihatkan penjelasan dari hasil rancangan lathe fixture untuk seluruh bagiannya. 


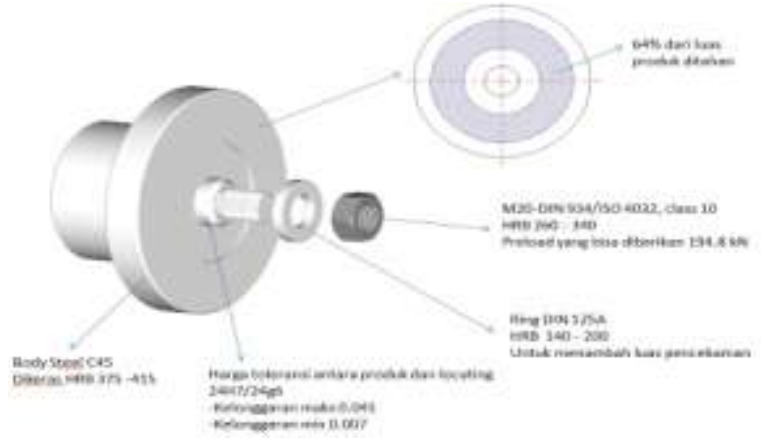

Gambar 10. Evaluasi hasil rancangan lathe fixture

Dari data-data yang dikumpulkan yang terdapat pada operasi 30 yang sekarang digunakan dan juga target yang ingin dicapai dibandingkan dengan kondisi hasil rancangan lathe fixture, maka analisa datanya adalah seperti "Table (6)" dan untuk analisa kondisi parameter pemesinan diperlihatkan pada Gambar 11.di bawah:

Tabel 6.Analisa hasil rancangan dari lathe fixture

\begin{tabular}{|c|c|c|c|c|c|c|}
\hline \multirow{2}{*}{ No } & \multirow{2}{*}{ Nettrisgz| } & \multirow{2}{*}{$\begin{array}{c}\text { Verdisiopas } \\
\text { Sekang }\end{array}$} & \multicolumn{2}{|c|}{ Tangt } & \multirow{2}{*}{$\begin{array}{l}\text { Analutatal } \\
\text { sancergan }\end{array}$} & \multirow{2}{*}{ 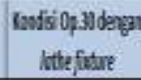 } \\
\hline & & & Viti & kathru & & \\
\hline \multicolumn{7}{|c|}{ AProndta Penesinan } \\
\hline & Depto of cut a-m & 100 & 158 & Kak & Bisa & 150 \\
\hline & 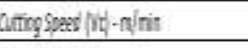 & BMO & mone & $\mathrm{Kak}$ & Bisa & and \\
\hline & Feed If-min & 1115 & as: & Kak & biad & 030 \\
\hline \multicolumn{7}{|c|}{ B.Wath } \\
\hline & 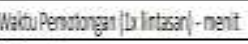 & {$[32$} & 0.15 & Tunn & Bisa & 0.19 \\
\hline \multicolumn{7}{|c|}{ CPewretanan } \\
\hline & ChudPresure-Npa & 132. & $2 x$ & Kak & Biad & 220 \\
\hline & Pariargygtiolen-mn & $45:$ & 1008 & $\mathrm{Kak}$ & bisa & 900 \\
\hline & Parjergyergabejagn-m & $115 \mathrm{n}$ & $7 \pi$ & Tunn & Bisa & $3 \pi$ \\
\hline \multicolumn{7}{|c|}{ 0. Gap IangTejafl (perthurgan) } \\
\hline & arfigg forez- N & 5050 & $1,1,2 \Omega$ & Kak & Bisa & $1,23 \Omega$ \\
\hline & centrifugelfone- $x$ & $4 \pi 10$ & 2710 & Tinn & bisa & 25730 \\
\hline & 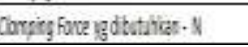 & 2,2810 & zi,790ue & Kak & Bisa & st. 1443 站 \\
\hline
\end{tabular}

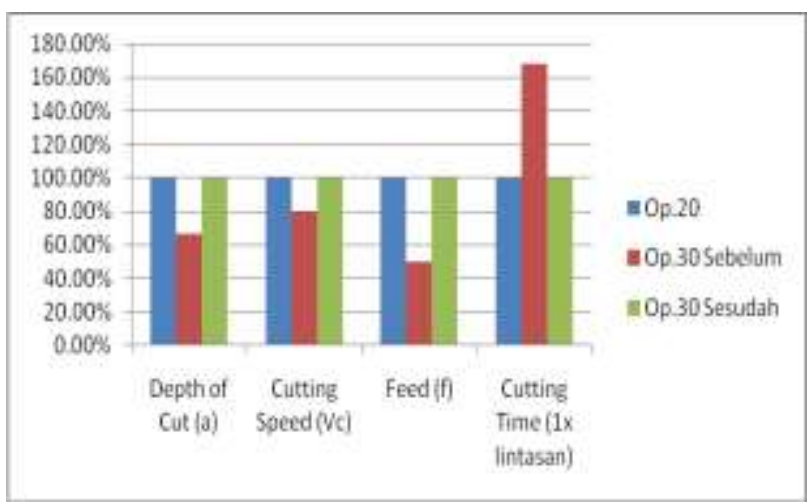

Gambar 11. Grafik kondisi parameter pemesinan operasi 30 sebelum dan sesudah menggunakan lathe fixture dengan mengacu kepada parameter pemesinan operasi 20.

\section{SIMPULAN DAN SARAN}

\section{Simpulan}

1. Bahwa lathe fixture dengan desain dan dimensi seperti yang penulis rancang secara teoritis akan mampu menahan gaya pemotongan yang ditimbulkan oleh adanya interaksi insert CNMG 120408-ML dengan produk poolschijf/402218716371 pada operasi 30 dengan menggunakan nilai cutting parameters yang sama dengan operasi 20.

2. Dengan menggunakan lathe fixture pada operasi 30 akan mendapatkan penghematan dari konsumsi kebutuhan material sehingga dengan material yang lebih pendek maka waktu pemotongan akan lebih cepat dan ongkos produksi akan menurun.

\section{Saran}

Berdasarkan hasil analisa dalam pembahasan penelitian ini maka penulis memberikan saran-saran kepada pembaca. Saran-saran tersebut adalah sebagai berikut:

1. Untuk mendapatkan gaya pencekaman yang optimal sesuai kebutuhan maka hendaknya diperhatikan dengan sungguh-sungguh gaya sentrifugal yang terjadi yang akan mengurangi gaya pencekaman seiring dengan meningkatnya putaran spindel.

2. Pada penelitian berikutnya hendaklah lebih dikembangkan dan lebih diperluas lagi ruang lingkupnya, bukan hanya pada kondisi penggunaan satu jenis insert saja. Akan tetapi bisa dikembangkan dengan diteliti penggunaan insert-insert yang lainnya dan juga penggunaan soft jaws yang lain pula.

3. Agar bisa mendapatkan perbandingan antara hasil rancangan secara teoritis dengan penggunaan secara langsung di lapangan dalam kondisi yang real maka rancangan lathe fixture untuk produk poolschijf/402218716371ini agar dilanjutkan ke tahap berikutnya yaitu dibuat produk jadinya. 


\section{DAFTAR PUSTAKA}

Henriksen, Jig and Fixture Design Manual, Industrial Press, New York, 1973.

Hoffman Edward, Jig and Fixture Design, Edisi kelima, Thomson, New York, 2004.

Ingersoll Taeguline, Taegutec Catalogue, 2007.

Isakov Edmund, Cutting Tool Engineering Magazine, Power Equations, Vol.53 no.5, May 2001.

Rochim Taufiq, Klasifikasi Proses, Gaya dan Daya Pemesinan, Buku 1 dan Buku 2, Penerbit ITB, Bandung, 2007.

SMW AUTOBLOK, Instruction Manul Quick Jaw Change Power Chuck Type KNCS$\mathrm{N}$.

Unterweiser M. Paul at.al, Heat Treater's Guide Standard Practise and Procedures for Steel, Edisi keempat, American Society for Metals, Ohio, 1987. 